\title{
Redes de capital social familiar en la región oriental de Jujuy (Argentina) durante las tres primeras décadas del siglo $\mathrm{XX}$
}

\section{Networks of social capital family in the east región of Jujuy (Argentina) during the first three decades of the 20th century}

\author{
Federico Fernández ${ }^{1}$
}

\begin{abstract}
Resumen
En esta investigación se analiza la utilización de la categoría capital social, y sus vinculaciones posibles con los procesos de acumulación relacional y movilidad espacial entre familias extensas con residencias múltiples dentro de la región oriental de la provincia de Jujuy. La principal fuente de información con la que se ha elaborado el trabajo proviene de un conjunto de actas bautismales realizadas entre los años 1902 y 1935 por sacerdotes de la Prelatura de Humahuaca de Jujuy, sobre la población residente en la región conocida como Valle Grande. Los resultados obtenidos tras el ordenamiento y el Análisis de Redes Sociales (ARS) de los datos consignados en las actas bautismales dan cuenta de una serie de pautas vinculares factibles de ser descritas bajo la categoría de capital social familiar.
\end{abstract}

Palabras claves: capital social, familia extensa, residencia múltiple, apadrinamientos bautismales.

\begin{abstract}
In this research analyzes the utilization of the social capital category, and its possible linkages with the processes of accumulation relational and spatial mobility between extended family with multiple residences within the eastern region of the province of Jujuy. The main source of information with which it has developed work, comes from a set of baptismal records made between 1902 and 1935 by priests of the Prelature of Humahuaca, Jujuy, on the population living in the region known as Valle Grande. The results obtained after the ordering and the analysis of social networks (ARS) data entered in the baptismal records, give account of a series of relational feasible to be described under the category of family social capital.
\end{abstract}

Keywords: social capital, extended family, residence multiple, baptismal godfathership.

Recibido: 6 abril 2016. Aceptado: 11 diciembre 2016

1 Investigador Asistente del Consejo Nacional de Investigaciones Científicas y Técnicas (CONICET-Argentina). Integrante de la Unidad Ejecutora de doble dependencia CISOR (CONICET-UNJu). Profesor adjunto de la cátedra Antropología Social y Cultural. FHyCSUniversidad Nacional de Jujuy. Dirección Postal: Calle Alférez Sobral 2776. CP. 4600. San Salvador de Jujuy, ARGENTINA. Email: antropo428@yahoo.com.ar 


\section{Introducción}

El actual departamento Valle Grande -unidad de análisis de la presente investigación- se encuentra ubicado geográficamente en el extremo suroriental de Jujuy (última provincia de la frontera norte de la República Argentina, situada en territorio colindante con los vecinos países de Chile y Bolivia). La cantidad de población que ha residido y reside actualmente dentro del área Valle Grande presenta niveles de variación menores entre el primer registro censal nacional del siglo XX realizado en 1914 , donde la población en todo el área fue de 1721 habitantes, $\mathrm{y}$ el último censo nacional del siglo XX realizado en el año 1991, en donde la población registrada para Valle Grande alcanzó los 1978 habitantes. ${ }^{2}$

Esta relativa baja cantidad y variabilidad en el crecimiento poblacional de Valle Grande durante décadas ha sido un disparador de preguntas de investigación para diferentes disciplinas y perspectivas de análisis. ${ }^{3}$ En una serie de estudios de antropología e historia centrados en el análisis de parentesco y la organización social realizados entre los años 2008 y 2015 (Ferreiro y Fernández, 2013; Fernández, 2013), se ha logrado establecer que gran parte de este bajo crecimiento reflejado en los datos duros censales se debe no solo al aislamiento geográfico y difícil acceso a la región presente desde hace siglos, sino que también puede ser comprendido a través del análisis de las características socioestructurales sobre las cuales se han configurado las relaciones pa-

2 Según los últimos censos nacionales (2001 y 2010), Valle Grande presenta una cantidad de población variable que ronda entre los 2300 y 2600 habitantes distribuidos en un total de 10 poblados dispersos alrededor de una zona montañosa que combina la vegetación y el clima de las yungas o selva de montaña, con el cordón montańoso andino de características secas que se eleva a una altura superior a los $3500 \mathrm{msnm}$. Todo el departamento Valle Grande puede ser dividido, tomando como referencia los espacios ecoambientales y los metros de altura sobre el nivel del mar, en dos grandes regiones: la región de altura ubicada entre los $2500 \mathrm{~m}$ y por arriba de los 3500 msnm (zona alta de Valle Grande), y un área que se encuentra por debajo de los $2500 \mathrm{~m}$ (zona baja de Valle Grande).

3 Para un análisis histórico general sobre el crecimiento y decrecimiento de la población de Valle Grande, puede consultarse el texto de Teruel, Lagos y Peirotti (2006). rentales en todo el área, especialmente la marcada endogamia de pueblo ${ }^{4}$ y la constante movilidad de los pobladores locales que practican la trashumancia de ganado.

La base económica dominante de los vallegrandinos desde aproximadamente mediados del siglo XVIII, y que persiste en la actualidad, ha sido el pastoreo de ganado (vacuno, caprino y en menor medida ovino) y la agricultura de secano realizada entre diferentes pisos de altura, y en zonas ecoambientales de características disimiles ubicadas en áreas pastoriles que presentan distancias relativamente largas entre sí. De este modo, la movilidad de la población en estos territorios montańosos y fragmentados desde el punto de vista físico y ecoambiental resulta una condición absolutamente necesaria para la sobrevivencia tanto individual como colectiva. Así pues, dentro de los múltiples espacios que los circundan, los vallegrandinos (tanto hombres como mujeres) recorren sus escarpados territorios junto a sus recuas de ganado, estableciendo circuitos estacionales de movilidad y aparcamiento con sus animales.

El enfoque analítico desarrollado por Jurgen Golte (2001) en torno a la racionalidad de la organización andina en territorios similares al área vallegrandina parece ajustarse bastante bien a lo que los pocos e incompletos registros históricos y contemporáneos dejan entrever para esta zona. En este sentido, y tal como lo señala Golte para el caso peruano, comprender la lógica de la movilidad y cooperación entre conglomerados parentales ubicados en distintas alturas (zona alta/zona baja), y los diferentes espacios (rurales y urbanos) que circundan a la región, resulta crucial para interpretar tanto las medidas cuantitativas como las variables cualitativas que se utilizan para el registro de estas poblaciones en particular.

Desde esta perspectiva, el bajo crecimiento intercensal de la población de Valle Grande debe ser comprendido teniendo en cuenta los ciclos de movilidad

4 La categoría endogamia de pueblo o endogamia local refiere a las uniones matrimoniales y padrinazgos de bautismo en donde las personas involucradas han pertenecido durante largos períodos al mismo poblado. Sobre este punto particular y su desarrollo analítico bajo la metodología de redes, se puede consultar el texto de Ferreiro y Fernández (2013). 
ganadera y agrícola locales, y la coincidencia o no de la actividad censal con estos circuitos de movilidad. Prueba de ello es lo que dejan entrever las actas matrimoniales y bautismales durante todo el siglo XIX y las primeras décadas del siglo XX, cuando el número de casamientos y bautismos a lo largo del territorio vallegrandino oscila de manera pendular de acuerdo al momento del ańo en el que los sacerdotes visitaban la región para llevar a cabo sus actividades eclesiásticas. Así, por ejemplo, mientras que a lo largo de ocho años (entre 1902 y 1910) se consignaron un total de 42 bautismos; entre $1930 \mathrm{y}$ 1935 (un total de cinco años) el registro bautismal asciende a 154 actas.

La forma familiar predominante a lo largo de décadas en Valle Grande ha sido la familia extensa con residencia múltiple. ${ }^{5}$ Esto les ha posibilitado a los conjuntos familiares vallistos el control necesario de los diferentes espacios ecológicos del medio que los circunda, utilizando de la forma más productiva posible la fuerza de trabajo familiar y parental. Una de las aristas de esta forma de organización local que perdura en los tiempos actuales se expresa en la aún marcada residencia múltiple de los pobladores vallegrandinos.

Durante el trabajo de campo etnográfico realizado en los principales poblados del departamento Valle Grande, y en una de las zonas urbanas circundantes al área como la ciudad de Humahuaca, he podido observar y constatar que en los meses de otoño e invierno existe una ausencia prolongada de gran parte de vecinos y parientes de los pueblos de altura, cuyas actividades se concentran en las zonas bajas de los alrededores del poblado cabecera (en este caso el pueblo de Santa Ana).

5 Estos grupos familiares, en el caso de Valle Grande, se encuentran compuestos por conjuntos de apellidos tradicionales que configuran ciclos matrimoniales y de apadrinamiento, constituyéndose en segmentos de apellidos asociados cuya fisonomía se asemeja a lo que Giovanni Levi ha denominado como frentes de parentesco, esto es: "[...] un conjunto de solidaridades, alianzas, deberes y derechos ejercidos y potenciales de carácter asimétrico y jerárquico, que provocan lazos diferenciales desigualmente distribuidos en concentraciones puntuales” (citado en Ferreiro y Fernández, 2013, p. 32).
Es bastante común escuchar hoy a los pobladores del valle hablar de sus viajes y estadías en diferentes puestos y residencias en poblados vecinos dentro del mismo departamento o afuera de éste. Dependiendo de las actividades realizadas, los moradores del valle pueden vivir fuera de su residencia en el poblado cabecera entre 15 y 20 días, volver por un par de semanas al pueblo, y luego retomar el circuito de viajes para cuidar el ganado, comprar mercaderías a bajo precio en las ciudades cercanas y "de paso", quedarse de visita por dos o tres semanas en casa de sus parientes consanguíneos o políticos residentes fuera del departamento.

Paradójicamente, esta dinámica que presentan los pobladores vallegrandinos desde hace cientos de ańos ha sido y es "traducida" por una parte de cierta literatura e historiografía provincial a la manera de un conjunto "tosco e impávido de gente perdida en las inmensidades de la montaña". ${ }^{6}$ Esta imagen producto del constructo ideológico de corte romántico y esencialista- se basa en parte en el desconocimiento de los procesos socioculturales e históricos sobre los cuales se construyeron y construyen las relaciones sociales hacia el interior y hacia afuera del área vallegrandina. Pero también es el producto de la asociación directa que se suele hacer entre marginalidad espacial o territorial y pasividad conductual. Una especie de determinismo geográfico que impacta sobre las nociones de movilidad y/o quietud de los sujetos sociales que transitan por aquellos imponentes paisajes montańeses.

En efecto, una primera impresión acerca de la organización social y los vínculos parentales actuales en el valle ofrecerá al viajero ocasional una imagen un tanto estática de la vida social local. Sin embargo, a poco andar por estos poblados alejados, es relativamente fácil advertir que todas las referencias de vecindad e invitaciones casuales de visitas entre pobladores locales no solo son dinámicas, sino que además giran en torno a algún grado de interreconocimiento basado en el apellido, los lugares de residencia y/o puestos ganaderos, y el grado de

6 Sobre este punto en particular, se puede consultar un artículo de Fernández (2010), titulado: "Cuerpos endurecidos: fútbol, violencia ritual y tensiones identitarias en los valles orientales de Jujuy”. 
parentesco. Así, por ejemplo, las charlas cotidianas giran en torno al estado de salud de la tía $(\mathrm{N})$, o las demoras temporales que tuvo el hermano de $(\mathrm{J})$ por haber perdido parte del ganado tras una crecida del río en el puesto.

En las líneas que siguen se analizarán las categorías teóricas y herramientas conceptuales que considero permitirán entender, de manera retrospectiva, las aberturas en las relaciones fuertemente endogámicas -no por ello estáticas- que han construido tradicionalmente los pobladores vallegrandinos.

\section{La noción de capital social y sus aplicaciones en el análisis formal de redes sociales}

La definición establecida por Pierre Bourdieu en torno a la categoría capital social se encuentra precedida por una serie de debates teóricos en torno no solo a la noción de capital en sí, sino también y fundamentalmente, acerca del volumen y la posición funcional que estos agrupamientos factibles de ser analizados bajo la categoría de capital (capital económico, capital cultural, capital simbólico) se relacionan y yuxtaponen entre sí de acuerdo a configuraciones estructurales específicas. ${ }^{7}$

Como lo señala Alicia B. Gutiérrez (2011), ciertos escritos de Bourdieu, especialmente aquellos donde el autor desarrolla sus ideas acerca del espacio social y el concepto de campo, permiten entrever que la importancia relativa del capital social como categoría analítica se encuentra vinculada con el peso que poseen las otras especies de capitales. De este modo, existen sociedades donde el capital económico y el capital cultural constituyen los ejes vertebrales de la estructura social. Pero también, dependiendo de las formaciones económicas e histórico-políticas de la sociedad en cuestión, el peso de cada uno de estos capitales varía en cuanto a su importancia y jerarquización.

7 Para un análisis detallado acerca de las categorías teóricas claves en la obra de Bourdieu, puede consultarse el texto de Alicia B. Gutiérrez (2011) "Clase, espacio social y estrategias", texto introductorio en la edición en español del libro de Pierre Bourdieu titulado Las estrategias de la reproducción social (Ed. Siglo XXI).
Las explicaciones que el mismo Bourdieu establece en torno a sus notas provisorias sobre la noción de capital social constituyen un claro ejemplo de la interdependencia que existe entre esta categoría y las demás especies de capitales. Para Bourdieu, "el capital social es el conjunto de recursos actuales o potenciales ligados a la posesión de una red durable de relaciones más o menos institucionalizadas de interconocimiento y de interreconocimiento" (2011, p. 221). Más adelante en el texto el autor aclara que la durabilidad temporal de esta red relacional no puede ser caracterizada sencillamente como una red per se, es decir, por el solo hecho de la existencia relacional entre individuos o grupos. Esto es:

La existencia de una red de vínculos no es un dato natural, ni siquiera un "dato social", constituido de una vez y para siempre por un acto social de institución (representado, en el caso del grupo familiar, por la definición genealógica de las relaciones de parentesco que es característica de una formación social), sino producto del trabajo de instauración y de mantenimiento necesario para producir y reproducir vínculos durables y útiles, adecuados para procurar beneficios materiales o simbólicos (Bourdieu, 2011, p. 222).

Se observa entonces que tanto la red como su durabilidad se encuentran "atravesadas" por la construcción y reproducción de otras dos especies de capitales (materiales [económico] y simbólico). Es precisamente esta última forma de capital la que Bourdieu utilizó originalmente para señalar una serie de relaciones específicamente ligadas a conjuntos familiares (lazos afectivos), y actos de confianza teñidos por la cercanía genealógica entre agentes sociales considerados como pares.

En el texto titulado El sentido práctico, Bourdieu analiza precisamente la aplicabilidad descriptiva y explicativa del capital simbólico en tanto relación que combina aspectos materiales e ideales de la realidad sociocultural. Esto es, el capital simbólico entendido como:

[...] la red de aliados y de relaciones a las que uno sostiene (y por los que uno se sostiene) a 
través del conjunto de los compromisos y las deudas de honor, de los derechos y deberes acumulados en el curso de las generaciones sucesivas y que puede ser movilizado en las circunstancias extraordinarias. Capital económico y capital simbólico están inextricablemente mezclados, que la exhibición de la fuerza material y simbólica representada por aliados prestigiosos es de una naturaleza tal que aporta de por sí beneficios materiales, en una economía de la buena fe donde un buen renombre constituye la mejor, si no la única, garantía económica (Bourdieu, 2007, p. 189).

La relación de interdependencia entre formas de capital (social, simbólico, económico) constituyen entonces los dispositivos analíticos centrales para el reconocimiento de las estrategias de agentes y conjuntos sociales dentro de formaciones socioeconómicas en contextos históricos específicos. Ahora bien, esta idea relacional y multidimensional sobre los vínculos económicos y sus expresiones sociosimbólicas ha sido desarrollada originalmente por Norbert Elias en su obra El proceso de la civilización. Investigaciones sociogenéticas y psicogenéticas, publicada en alemán en el año 1977 (tomo I). Aquí Elias, al analizar la formación histórica de la clase media y la nobleza cortesana alemana en comparación con su homóloga francesa señala que:

Las unidades sociales a las que llamamos naciones se distinguen unas de otras en gran medida en función de su forma de organizar su economía afectiva, esto es, según los esquemas por los cuales se modela la vida afectiva del individuo a través de una tradición que se ha hecho institucional, así como a través de la situación actual (Elias, 2012, p. 112).

Es precisamente en esta obra de carácter sociológico e histórico donde Elías logra conjugar aspectos económicos y simbólicos de conjuntos sociohistóricos particulares, y al mismo tiempo establece que la modelación de los comportamientos afectivos se encuentra atravesada precisamente entre ambas dimensiones (económicas y simbólicas) inextricable- mente mezcladas, como lo señaló posteriormente Bourdieu.

Según Molina, Muñoz y Losego (2000), la aplicabilidad de este complejo y multifacético concepto de capital social dentro del universo investigativo teórico cercano al Análisis de Redes Sociales (ARS) tuvo como base la idea seminal del modelo propuesto por Mark Granovetter en 1973, quien establece la distinción entre vínculos fuertes y débiles, teniendo en cuenta la frecuencia, intensidad y cercanía de los lazos entre individuos. Más específicamente, desde la perspectiva de Granovetter, los vínculos débiles son definidos como relaciones de baja intensidad en términos de inversión sociotemporal entre los agentes inmersos dentro de una red vincular. Por el contrario, los lazos fuertes refieren a aquellas relaciones caracterizadas como frecuentes en términos sociotemporales, y de mayor estabilidad (a largo plazo) en lo que respecta a los agentes involucrados en la relación.

Tal como lo han señalado Woolcock y Narayan (2000), ${ }^{8}$ la noción elemental de capital social sugiere la idea de que los procesos de sociabilidad tanto primarios (núcleo familiar y parientes cercanos) como secundarios (instituciones escolares, asociaciones civiles, conjuntos barriales, etc.) constituyen un "activo" importante al momento de obtener beneficios materiales y/o "soportar", ya sea en términos individuales como grupales, las profundas desigualdades e inequidades de las sociedades complejas contemporáneas.

En el apartado referido específicamente al enfoque de redes y la dimensión analítica que comprende el concepto de capital social, ambos autores subrayan la importancia de la perspectiva de redes al considerar y diferenciar tanto las relaciones horizontales entre pares (bonding) como así también las asociaciones de carácter más vertical y tendientes a relacionar conjuntos sociales generalmente asimétricos entre sí (bridgin). Desde este enfoque, sería factible entonces reconocer determinados entramados sociales

8 Agradezco a los evaluadores y/o evaluadoras del presente texto la sugerencia de la lectura del texto publicado por Woolcock M., y Narayan, D., "Social Capital: Implications for Development Theory, Research, and Policy”. 
trazados por individuos y grupos en pos de la acumulación relativa de relaciones sociales en determinados contextos comunitarios y extracomunitarios.

Ahora bien, y volviendo al punto de partida de la distinción entre lazos débiles y lazos fuertes en relación a la noción general de capital social, ¿̇con qué criterios es posible definir la intensidad (baja o alta) y la frecuencia de los vínculos en casos de estudios centrados en grupos familiares y vínculos parentales? Los escritos de Frank F. Furstenberg (2005) en "Banking on Families: How Families Generate and Distribute Social Capital”, circunscriben esta incógnita en el ámbito específico de la sociología e historia de la familia. Para Furstenberg, no está del todo claro cuáles serían los mecanismos intrafamiliares de distribución y acumulación del capital social entre grupos de personas emparentadas entre sí. En efecto, estos mecanismos se encuentran determinados en la mayoría de los casos por los contextos culturales e históricos que definen los usos del capital social entre y para con los conjuntos familiares y parentales relacionados. Así pues, siguiendo a Furstenberg, en el apuro de intentar medir las variantes en los usos del capital social familiar, la mayoría de las investigaciones se centran más en la conveniencia de tomar tal o cual criterio de medición de acuerdo a sus interés de investigación, que en el rigor conceptual que exigen las caracterizaciones teóricas y metodológicas en torno a las formas de acumulación y distribución de vínculos factibles de ser medidos como capital social en el ámbito familiar y parental.

\section{Capital social familiar y apadrinamientos bautismales}

En la presente investigación se tomó como un primer eje problematizador la idea planteada por Furstenberg en torno a los criterios a utilizar para medir y/o cualificar la fuerza o debilidad de los lazos familiares bajo el concepto de capital social familiar. Para este autor, las nociones de capital social, redes parentales y vínculos familiares deben ser diferenciadas en relación a sus capacidades para invocar normas comunes y fortalecer los niveles de confianza, lo cual impacta necesariamente en las creencias y obligaciones recíprocas que genera este tipo particular de vínculos entre los miembros que comparten pautas comunes de sociabilidad e intercambio. Ahora bien, siguiendo a Furstenberg, es necesario establecer de la forma más rigurosa posible los distintos niveles y/o dimensiones del capital social en relación a conjuntos parentales y familiares, para luego "re-construir" y al mismo tiempo diferenciar las posibles "puertas" de acceso a determinado capital social (contextos de apertura), de los usos intrafamiliares de lazos tendientes a la generación de un determinado capital social familiar.

Teniendo en cuenta esta premisa general, los componentes de horizontalidad y verticalidad de los vínculos referidos en el citado texto de Woolcock y Narayan constituyen un segundo horizonte conceptual a través del cual se pretende caracterizar el cierre (intracomunidad o hacia dentro de los frentes de parentesco) de las redes mapeadas, como así también las aperturas o puentes (bridgin) expresados según determinadas categorizaciones dentro de los contextos históricos y las características socioculturales que son inherentes a la presente investigación.

Esto último no resulta un hecho menor ya que, a diferencia del análisis fundamentalmente conceptual y teórico de los trabajos de Woolcock y Narayan sobre el capital social en tiempos contemporáneos, la presente pesquisa se basa en la reconstrucción estructural y categorial de fragmentos de escritos del pasado, interpretados desde el tiempo presente del etnógrafo. Esto implica, en primer lugar, una caracterización sociohistórica de la unidad de análisis tal como se ha pretendido resumir en el apartado introductorio, $y$, en segundo lugar, tener un especial cuidado en la no extrapolación de categorías teóricas válidas para el presente, pero no así para el caso de sociedades donde la presencia del Estado y las organizaciones civiles locales no exhiben, aun en la actualidad, el robustecimiento institucional que las ha caracterizado en otras regiones, incluso dentro de la misma provincia de Jujuy.

El área de Valle Grande se ha distinguido tradicionalmente por una marcada endogamia local o de pueblo, tanto en lo que respecta a los circuitos matrimoniales como en lo referente a la elección de compadres y comadres locales. Teniendo en cuenta estas características socioparentales centrales, resulta necesario establecer claramente qué diferencias han 
sido establecidas por los vallegrandinos en lo que respecta a familiares consanguíneos y parientes por afinidad.

La evidencia etnográfica contemporánea muestra que la figura de los padrinos y/o madrinas de bautismo representa para los vallegrandinos católicos una especie de "cuasi-familiar", en tanto no presenta vínculo de sangre, pero significa, bajo determinadas condiciones, un sustento afectivo, económico y simbólico similar al de un pariente de sangre (hermano, tío, primo). Ahora bien, ¿cuál es la profundidad histórica de este tipo particular de vínculo?

La fuerza y el contenido de los vínculos y los actos rituales ligados a las relaciones de compadrazgo han sido objeto de profundos estudios en el espacio latinoamericano. ${ }^{9}$ El caso de los apadrinamientos bautismales -un tipo particular de ritual religioso de origen católico- constituye solo uno de los acontecimientos liminales a través de los cuales el individuo y su grupo familiar más cercano establecen un conjunto de compromisos, deberes y derechos que se expresan, en la mayoría de los casos, a lo largo de ańos de relaciones entre las partes que sellan este acto eclesiástico.

Tal como lo señalan White, Schnegg, Brudner y Nutini (2002), los bautismos católicos originarios del viejo continente han sido transformados en el espacio latinoamericano en tres puntos centrales:

En primer lugar, la díada más importante de la relación triádica, que en la doctrina católica era la constituida por los lazos entre el niño y sus padrinos, se desplazó hacia la relación entre los padres y los padrinos, es decir, entre los compadres y las comadres. En segundo lugar, el objeto (el niño en la tradición europea) mediante el que se establecía la conexión del compadrazgo, dejó de limitarse a las personas y pasó a incluir otros objetos. En tercer lugar, y respecto a lo anterior, las

9 Sobre los estudios de diferentes rituales de apadrinamiento en Latinoamérica, se pueden consultar los trabajos de Albo y Mamaní (1980) para casos bolivianos, Nutini (1989) para México, y Lomnitz (1994) para casos chilenos. ocasiones en las cuales podía establecerse una relación de parentesco ritual se extendió a muchos otros acontecimientos autóctonos, religiosos o seculares. (White y otros, 2002, pp. 43, 44).

Esta caracterización general realizada por los autores expresa claramente lo que ocurre con las relaciones de compadrazgo, no solo en el área de Valle Grande, sino también en gran parte de los sectores populares del Noroeste Argentino (NOA).

En lo que respecta a la unidad de análisis de la presente pesquisa, la aparición de compadres y comadres foráneos comienza a hacerse visible y significativa en las actas de bautismo registradas entre pasada la mitad del siglo XIX y principios del XX. Esta apertura en el "círculo endogámico" a partir de la incorporación de padrinazgos foráneos se encuentra evidenciada en la aparición progresiva de padrinos y madrinas bautismales portadores de apellidos con baja tradición temporal dentro del departamento. Tal correlación entre datos de "nuevos compadres y comadres" se da justamente tiempo antes y continúa con posterioridad al año 1887 , período en el cual referentes de las familias originarias-campesinas del área realizan la compraventa de sus terrenos para la construcción de residencias, espacios de cultivo y actividades ganaderas; lo cual me ha sugerido la idea de que el crecimiento de lazos de apadrinamientos exógenos a Valle Grande durante este período, pudo estar asociado con la "búsqueda" por parte de pobladores originarios del valle de compadres y/o comadres que permitan el acceso a préstamos de dinero necesario para comprar tierras en el espacio vallegrandino.

En un texto posterior al planteo realizado en el párrafo precedente (Fernández, 2013), he descripto a través del análisis de actas bautismales y el ordenamiento de estos datos bajo el formato métrico-relacional de redes sociales, alguno de los procesos de cambio y continuidad entre las denominaciones de los individuos más buscados como padrinos/madrinas de bautismo en la región vallegrandina desde mediados del siglo XIX hasta los primeros ańos del siglo XX. Los resultados obtenidos de esta investigación, muestran que a medida que crece el número de ahijados en manos 
de determinados padrinos/madrinas y/o parejas de padrinos, el nombre de estos últimos comienza a ser inscripto en las sucesivas actas con los términos "Don o Doña" precediendo al nombre y apellido de la persona en cuestión. Esta forma particular de registro permite pensar la inscripción Don o Doña a la manera de un marcador de estatus expresado de manera escrita. Así, por ejemplo, el nombre Alberto Murga pasa a ser registrado por el mismo sacerdote después de un crecimiento en los apadrinamientos en manos de A. Murga como "Don Alberto Murga".

En los testimonios de los actuales memoriosos vallistos, los padrinos y/o madrinas de bautismo aparecen como individuos cercanos al núcleo familiar (el apellido, la residencia y la tierra), pero al mismo tiempo alejado de lo que podríamos denominar como el núcleo duro genealógico local. En efecto, en muchos de los casos recordados en la actualidad, los padrinos y/o madrinas de bautismo residieron o residen en las afueras del pueblo, pero dentro del mismo departamento y/o en las ciudades cercanas al departamento Valle Grande. Asimismo, otro de los rasgos comunes que presentan padrinos y madrinas bautismales en la actualidad es el de ser considerados por los progenitores de los nińos/niñas ahijados como personas "respetadas", es decir, vinculadas de algún modo a familias con apellidos de larga tradición en la región y/o con actividades profesionales de alto valor en el espacio local como lo es la actividad docente en instituciones educativas locales. ${ }^{10}$

Una situación similar es la que Alison Spedding (1998) ha seńalado para la región Sud-Yungas de Bolivia. Aquí los padrinos de primer corte de pelo (murucha) -un ritual cuya cronología y alcance en esta región de Bolivia es mucho más amplio que el acto bautismal católico- son seleccionados por los padres (futuros compadres) de la niña o el niño de acuerdo a una serie de criterios previos. Así, por ejemplo: "Personas solicitadas como compadres incluyen miembros respetados y acomodados de la misma comunidad, dueños de camiones en la mis-

10 La información de que docentes de las escuelas primarias son considerados con un alto estatus, en especial si son foráneos a la región vallegrandina, ha sido también registrada por Cladera (2015) en su tesis de maestría en Antropología. ma comunidad o en las comunidades vecinas y, con menos frecuencia, personas acomodadas del pueblo" (Spedding, 1998, pp. 129-130).

Teniendo en cuenta estos antecedentes de investigación sobre la importancia social de los vínculos de apadrinamiento en el área Valle Grande y en zonas similares, en el presente texto se plantea como hipótesis de trabajo la caracterización de las relaciones de apadrinamientos bautismales vallegrandinos a la manera de una red relacional de carácter afectivo y duradera en el tiempo (capital social familiar), basada en la movilización y mantenimiento de recursos y/o servicios (capital simbólico y económico), que tuvieron que exigir una inversión temporal y económica por parte de quienes conformaban y sustentaban esta red. Como se verá más adelante, de acuerdo a los resultados obtenidos tras la seriación de la información presente en un conjunto de actas bautismales distribuidas en cuatro períodos temporales predefinidos, los vínculos de apadrinamiento en manos de individuos foráneos al área vallegrandina, varían conforme al crecimiento o decrecimiento porcentual de nacimientos consignados como hijos/ hijas naturales e hijas/hijos legítimos.

Hacia el final del texto, un vez expuesta la información ordenada en el espacio topológico de las redes, se dará una explicación posible sobre cuáles fueron los criterios locales (tendencias y/o regularidades) que subyacieron a las selecciones de determinados padrinos/madrinas bautismales, y qué factores de interreconocimiento configuraron la constricción (bonding) y/o apertura (bridgin) de las redes de apadrinamiento dentro de estos conglomerados parentales organizados bajo la forma de familia extensa con residencias múltiples.

\section{Aspectos metodológicos y fuentes de la investigación}

El análisis de redes sociales entendido como herramienta metodológica tiene como punto de partida el establecimiento de vínculos entre diferentes tipos y dimensiones de la información con la que trabajamos investigadoras e investigadores de diferentes disciplinas científicas. Sin embargo, el corpus teóricoconceptual que precede al trabajo con la información 
factible de ser transformada en una red relacional constituye el soporte base sobre el cual se erige cualquier tipo de decisión metodológica.

Tal como ya se ha reseñado en el apartado anterior, una de las derivaciones posible de las categorías teóricas desarrolladas en torno al concepto de capital social es aplicable en el microuniverso de los estudios formales de redes tomando las categorías planteadas originalmente por Marx Granovetter en torno a sus ideas sobre lazos fuertes y lazos débiles. ${ }^{11}$

Los argumentos esgrimidos por Furstenberg en torno al capital social familiar permiten circunscribir de manera operativa el acceso y el uso de determinados bienes materiales y/o servicios, enfocándolos en la dinámica social singular que presentan los conjuntos parentales. Asimismo, y con el objeto de obtener una mayor precisión de los momentos de apertura y/o cierre de la red a nivel conceptual, se tendrán en cuenta las nociones de horizontalidad y verticalidad de las relaciones planteadas por Woolcock y Narayan y sus vinculaciones posibles con la reconstrucción histórica de los vínculos mapeados.

Un primer ordenamiento de los datos presentes en las actas bautismales se realizó siguiendo los siguientes tres criterios: a) la categorización usada en las actas para designar a los individuos involucrados en la red (madre/padre, hijo/hija, padrino/madrina), b) el lugar de residencia de los individuos consignados en las actas (origen y residencia de la madre, padre, hijo o hija, padrino, madrina, y c) la legitimidad o ilegitimidad del vínculo entre progenitores y sus hijos/ hijas según fueron consignados en las actas (hijo/a legítimo, hijo/a natural).

11 El análisis desarrollado por Freeman (2002) sobre cómo detectar grupos sociales en datos cuantitativos refiere a un tipo de cálculo utilizado por M. Rapoport basado en la transitividad de las relaciones grupales expresadas a través de matrices de redes. Este modelo refiere de forma directa a lo planteado originalmente por Granovetter en torno a los vínculos débiles y fuertes, y se denomina Modelo G-Transitivo. Dadas las características de la información trabajada en esta pesquisa, y el tipo de matriz utilizada, no es posible aplicar de manera directa a los datos este modelo de cálculo basado en la transitividad de los lazos.
Cada uno de estos criterios -surgidos de la información presente en las actas- constituyó la estructura sobre la cual se ha edificado el proceso de codificación de los datos para transformarlos luego en nodos. A partir de los criterios (a y b), se crearon las categorías referidas a los apadrinamientos bautismales combinados, es decir, aquellos compadres y/o comadres elegidos por los progenitores (ya sea solo la madre y/o la pareja conyugal), cuya residencia fuese registrada como fuera del mismo poblado de la madre y/o el padre del niño/niña bautizado, pero dentro del mismo departamento. También teniendo en cuenta estos dos criterios, se han agrupado en la categoría de apadrinamientos foráneos al departamento, solo aquellos compadres y/o comadres que residían en poblados exógenos al área Valle Grande y que fueran elegidos por los progenitores que figuran en las respectivas actas. En el punto c), se agruparon los hijos/hijas (ahijados/ahijadas) según fueron consignados en las actas como hijo/a legítima o hijo/a natural.

En la siguiente tabla (Tabla 1) se expresan en columnas separadas la cantidad de registros (actas) según fueron consignados para cada agrupamiento tempo$\mathrm{ral}^{12}$ y las categorías resultantes de los criterios de selección a), b) y c).

12 Como se puede observar en la Tabla 1, las cantidades de registro son muy disímiles entre sí. Estas marcadas diferencias en las cantidades de bautismos por períodos se deben a lo que ya se ha señalado al inicio del presente texto. Esto es, los meses en los que se llevaron a cabo in situ estas actas eclesiásticas. Especialmente en el período II no se corresponde con la presencia mayoritaria en los poblados cabecera de los progenitores, hijos/hijas y padrinos/madrinas; a esta situación habría que sumarle la muy baja frecuencia de visitas por parte de sacerdotes al área Valle Grande entre 1911-1922 por razones que aún no he logrado dilucidar. 
Tabla 1

\begin{tabular}{|c|c|c|c|c|c|}
\hline Períodos & $\begin{array}{c}\text { Total de } \\
\text { registros }\end{array}$ & Apadrinamientos combinados & $\begin{array}{c}\text { Apadrinamientos } \\
\text { foráneos al departamento }\end{array}$ & $\begin{array}{c}\text { Hijos } \\
\text { Naturales }\end{array}$ & $\begin{array}{c}\text { Hijos } \\
\text { Legítimos }\end{array}$ \\
\hline $\begin{array}{l}1902-1910 \\
\text { (Período I) }\end{array}$ & 64 & $4(6 \%)$ & $38(59 \%)$ & $30(47 \%)$ & $34(53 \%)$ \\
\hline $\begin{array}{l}1911-1922 \\
\text { Período II) }\end{array}$ & 26 & $0(0 \%)$ & $17(65 \%)$ & $11(42 \%)$ & $15(57 \%)$ \\
\hline $\begin{array}{l}1923-1930 \\
\text { Período III) }\end{array}$ & 154 & $40(25 \%)$ & $18(12 \%)$ & $57(37 \%)$ & $97(63 \%)$ \\
\hline $\begin{array}{l}1930-1935 \\
\text { (Período IV) }\end{array}$ & 154 & $44(28 \%)$ & $19(12 \%)$ & $31(20 \%)$ & $123(80 \%)$ \\
\hline
\end{tabular}

Fuente: Elaboración propia.

Una comparación general de las columnas y filas de la tabla 1 permite establecer que en los casos en los que los hijos naturales consignados superan la línea del 40\% (período temporal I y II), los apadrinamientos foráneos son relativamente altos, es decir, superan la línea del 50\% del total de los registros. Por el contrario, tal como se puede observar para el período III y IV, cuando la cantidad de hijos naturales no supera la línea del 40\% (como máximo llega al $37 \%$ en el período III), los apadrinamientos foráneos presentan porcentajes marcadamente menores (12\% para cada uno de estos dos últimos períodos).

Tras un segundo proceso de codificación de los datos para el armado de matrices, se reagruparon las categorías de apadrinamientos combinados y apadrinamientos foráneos al departamento Valle Grande, teniendo en cuenta de manera más específica el territorio donde aparecen consignados los padrinos / madrinas bautismales. Así pues, para el armado de las matrices se establecieron los siguientes criterios de agrupamiento: 1) Apadrinamientos locales (refiere a los vínculos entre progenitores y padrino-madrina que residieron estrictamente en el mismo poblado dentro de Valle Grande). 2) Quebrada (incluye a comadres y compadres foráneos al departamento y consignados en alguno de los poblados pertenecientes a la Quebrada de Humahuaca). 3) Valle (incluye a comadres y compadres que residieron en los poblados ubicados en los valles templados de la provincia). 4) Puna (incluye a comadres y compadres foráneos al departamento consignados en alguno de los poblados de la puna jujeńa). 5) Valle Grande Zona Alta (incluye a comadres y compadres que residieron en la zona alta del departamento). Valle Grande Zona Baja (incluye a comadres y compadres que residieron en la zona baja del departamento). 6) Padrinos y madrinas registrados como residentes en otro país (p.e. Bolivia) y/u otras provincias (p.e. Salta). Teniendo en cuenta estas seis clasificaciones, se elaboraron las matrices que dieron como resultado una distribución métrica y topológica específica para cada período temporal.

\section{Centralidad, facciones y redes}

En el lenguaje técnico del Análisis de Redes Sociales (ARS), existen dos formas básicas de crear una matriz de datos de tipo relacional. Se trata de lo que comúnmente se conoce como cuadros de doble entrada construidos con categorías ubicadas en las columnas y filas principales del cuadro. Las matrices denominadas de modo 1 (MMI) son cuadros de doble entrada cuadrados, es decir, la cantidad de las categorías presentes tanto en filas como en columnas es exactamente la misma. La principal diferencia entre las MMI y las matrices de modo 2 (MM2) se encuentra en la disimilitud presente en la cantidad de columnas y filas, es decir, las MM2 son matrices no cuadradas. La decisión de trabajar con una u otra matriz se encuentra estrechamente relacionada con el tipo de información y los objetivos que los investigadores se han propuesto. En este caso en particu- 
lar, he optado por el formato de MM2 debido tanto a intereses teóricos como al tipo de información que me he planteado analizar. ${ }^{13}$ Esto es, dado que uno de los propósitos de la pesquisa es establecer posibles correlaciones entre datos y categorías analíticas disímiles entre sí, las redes de modo 2 constituyen una opción metodológica y técnica que he considerado apropiada para el análisis de la información presente en las fuentes históricas tratadas.

Como ya se ha señalado hacia el final del apartado sobre aspectos metodológicos y fuentes de la investigación, el segundo proceso de codificación de los datos implicó la construcción de categorías de mayor precisión surgidas a partir del ordenamiento de las actas. Las MM2 con las que se trabajó contienen entonces las categorías descriptas que fueron ubicadas en la parte superior del eje horizontal de la matriz, mientras que en el eje vertical principal de esta misma matriz, se colocaron, bajo una sola codificación numérica, la madre y/o la pareja que figuran como progenitores del niño/niña bautizado.
Una vez ordenados los datos de este modo, la representación esquemática de la matriz que queda expresada es la siguiente:

Los números en las columnas de la Tabla 2 refieren al código que señala en el acta a la madre y/o la pareja que figuran como progenitores del niño/niña bautizado, mientras que las categorías ubicadas en la parte superior de las filas dentro de esta misma tabla señalan el lugar de residencia de comadres y compadres, y las dos últimas filas superiores hacen referencia a la legitimidad o no del niño/niña bautizada según consta en las actas. Los números 1 y 0 en el interior de la tabla 2 refieren respectivamente a la presencia (1), o ausencia (0) del vínculo entre la madre o pareja progenitora, y las diferentes categorías que figuran en las filas.

Uno de los cálculos que se ha tomado como referencia teniendo en cuenta las características de las matrices elaboradas ha sido el grado de centralidad.

Tabla 2. Ejemplo de MM2

\begin{tabular}{|c|c|c|c|c|}
\hline & Apadrinamientos Locales & Apadrinamientos Extralocales & Hijos Legítimos & Hijos Naturales \\
\hline 1 & 0 & 1 & 0 & 1 \\
\hline 2 & 1 & 0 & 0 & 1 \\
\hline 3 & 1 & 0 & 0 & 1 \\
\hline 4 & 0 & 1 & 0 & 1 \\
\hline 5 & 0 & 1 & 0 & 1 \\
\hline 6 & 0 & 1 & 1 & 0 \\
\hline 7 & 0 & 0 & 1 & 0 \\
\hline 8 & 1 & 0 & 0 & 1 \\
\hline 9 & 1 & 0 & 1 & 0 \\
\hline 10 & 1 & 0 & 0 & 1 \\
\hline 11 & 1 & 1 & 1 & 0 \\
\hline
\end{tabular}

Fuente: Elaboración propia.

13 Para un análisis detallado sobre la lógica de funcionamiento y los índices de medida aplicables a las MM2, se puede consultar el texto de Borgatti y Everett (1997) citado en la bibliografía. 
Tabla 3. Período I (1902-1910)

\begin{tabular}{|l|c|}
\hline \multicolumn{1}{|c|}{ Categorías } & $\begin{array}{c}\text { Centralidad de grado } \\
\text { normalizada }\end{array}$ \\
\hline Apadrinamientos Locales & $\mathbf{0 . 3 8 5}$ \\
\hline Hijos Naturales & $\mathbf{0 . 4 7 7}$ \\
\hline Hijos Legítimos & $\mathbf{0 . 5 2 3}$ \\
\hline Quebrada & $\mathbf{0 . 4 3 1}$ \\
\hline Valle & 0.015 \\
\hline Puna & 0.015 \\
\hline Valle Grande Zona Alta & 0.108 \\
\hline Valle Grande Zona Baja & 0.031 \\
\hline Bolivia & 0.015 \\
\hline
\end{tabular}

Fuente: Elaboración propia.

Tabla 4. Período II (1911-1922)

\begin{tabular}{|l|c|}
\hline \multicolumn{1}{|c|}{ Categorías } & $\begin{array}{c}\text { Centralidad de grado } \\
\text { normalizada }\end{array}$ \\
\hline Apadrinamientos Locales & $\mathbf{0 . 3 4 6}$ \\
\hline Hijos Naturales & $\mathbf{0 . 4 2 3}$ \\
\hline Hijos Legítimos & $\mathbf{0 . 5 7 7}$ \\
\hline Quebrada & $\mathbf{0 . 5 7 7}$ \\
\hline Valle & 0.000 \\
\hline Puna & 0.000 \\
\hline Valle Grande Zona Alta & 0.077 \\
\hline Valle Grande Zona Baja & 0.000 \\
\hline Bolivia & 0.000 \\
\hline
\end{tabular}

Fuente: Elaboración propia.

Tal como lo ha señalado Hanneman (2001), la centralidad de grado constituye una unidad de medida que contempla solo la cantidad de vínculos directos emitidos y/o recibidos por un nodo. ${ }^{14}$ En el caso particular de las MM2, la medida de centralidad

14 Es necesario aclarar aquí que tanto los códigos numéricos señalados como las categorías establecidas en la fila superior de la matriz son entendidos en el lenguaje técnico del ARS como nodos o vértices, mientras que las líneas que unen a estos nodos son denominadas como lazos o aristas.
Tabla 5. Período III (1923-1930)

\begin{tabular}{|l|c|}
\hline \multicolumn{1}{|c|}{ Categorías } & $\begin{array}{c}\text { Centralidad de grado } \\
\text { normalizada }\end{array}$ \\
\hline Apadrinamientos Locales & $\mathbf{0 . 7 2 7}$ \\
\hline Hijos Naturales & $\mathbf{0 . 3 2 7}$ \\
\hline Hijos Legítimos & $\mathbf{0 . 6 7 3}$ \\
\hline Quebrada & $\mathbf{0 . 0 9 3}$ \\
\hline Valle & 0.005 \\
\hline Puna & 0.010 \\
\hline Valle Grande Zona Alta & 0.078 \\
\hline Valle Grande Zona Baja & 0.063 \\
\hline Salta & 0.024 \\
\hline
\end{tabular}

Fuente: Elaboración propia.

Tabla 6. Período IV (1930-1935)

\begin{tabular}{|l|c|}
\hline \multicolumn{1}{|c|}{ Categorías } & $\begin{array}{c}\text { Centralidad de grado } \\
\text { normalizada }\end{array}$ \\
\hline Apadrinamientos Locales & $\mathbf{0 . 7 1 4}$ \\
\hline Hijos Naturales & $\mathbf{0 . 2 0 8}$ \\
\hline Hijos Legítimos & $\mathbf{0 . 7 9 2}$ \\
\hline Quebrada & $\mathbf{0 . 1 3 6}$ \\
\hline Valle & 0.000 \\
\hline Puna & 0.026 \\
\hline Valle Grande Zona Alta & 0.058 \\
\hline Valle Grande Zona Baja & 0.065 \\
\hline Salta & 0.000 \\
\hline
\end{tabular}

Fuente: Elaboración propia.

debe ser calculada teniendo en cuenta no ya la red total, sino los grados normalizados tal y como se expresan en las Tablas 3, 4, 5 y 6, correspondientes a los períodos temporales I, II, III y IV.

Los grados de centralidad normalizados de mayor peso han sido marcados con negrita en cada uno de los períodos. Para el período I (Tabla 3), se observa que las categorías con mayor cantidad directa de asociaciones recibidas, y que fueran emitidas desde la codificación numérica (madre y/o pareja 
progenitora), son las etiquetadas con el nombre de Hijos Legítimos (0.523), seguido de Hijos Naturales (0.477), Quebrada (0.431) o su equivalente que sería en este caso la categoría de Apadrinamientos Extralocales, y Apadrinamientos Locales (0.385). Se puede observar aquí que, tomando en cuenta los vínculos directos, la categoría referida a Hijos Naturales se encuentra a pocos grados de diferencia de la categoría Quebrada, mientras que las dos etiquetas restantes se encuentran separadas por varios grados de diferencia. Esto implica básicamente que existe un rango similar de actividad consignada en las actas donde se refiere a las relaciones entre madres con hijos naturales, y comadres y/o compadres residentes en la Quebrada de Humahuaca.

Para el período II (Tabla 4) ocurre algo similar a lo que se expresa en el período anterior, aunque con algunas particularidades. Si bien aquí, a diferencia del primer período, Hijos Legítimos y Quebrada presentan la misma centralidad de grado (0.577), la diferencia entre las categorías Hijos Naturales y Quebrada sigue siendo menor que los grados existentes entre Apadrinamientos Locales e Hijos Legítimos.

$\mathrm{Al}$ aplicar el análisis de facciones en redes ${ }^{15}$ de modo dos que se encuentra dentro del paquete UCINET 6 (programa informático diseñado para el análisis formal de redes), los resultados obtenidos para las matrices correspondientes a los períodos I y II dan cuenta de una mayor densidad de vínculos concurrentes entre las categorías Hijos Naturales y Apadrinamientos Extralocales a Valle Grande, en su mayoría provenientes de la región Quebrada. Tal medida de densidad estaría marcando una fuerte asociación entre ambas categorías, es decir, un agrupamiento

15 Se sigue aquí el enfoque general propuesto por Hanneman (2001), para quien las facciones se corresponden con una forma de agrupamiento (subestructuras) dentro de una red de relaciones expresadas tanto en matrices de datos como en los gráficos de redes. A diferencia del análisis de centralidad donde solo se contabilizan los vínculos directos, la medida de facción permite el reconocimiento de una mayor o menor densidad entre los vínculos que presentan los nodos de acuerdo a una serie mínima de dos particiones. Esto posibilita, a través del uso de la función Network que se encuentra dentro del programa UCINET 6, agrupar a los datos-nodos de la matriz de acuerdo a la similitud y/o disimilitud existente en los patrones de conexión. de conjunto entre etiquetas que a priori se presentan como independientes unas de otras.

Las centralidades de grado para el período III (Tabla 5) y IV (Tabla 6) expresan claramente una imagen opuesta en cuanto a los datos de las primeras dos tablas. En estos últimos agrupamientos temporales, Hijos Legítimos y Apadrinamientos Locales presentan la menor diferencia en lo que respecta a la centralidad de grado, mientras que Hijos Naturales y Quebrada se encuentra en el penúltimo y último lugar tomando como referencia los mayores cuatro índices de centralidad en ambas tablas.

Al igual que para las tablas del período I y II, se utilizó aquí también el análisis de facciones dando como resultado un mayor índice de densidad concurrente entre las categorías de Hijos Legítimos y Apadrinamientos Locales para los períodos III y IV. El resto de las etiquetas de estas últimas dos matrices presentan una dispersión mayor comparadas con los dos períodos anteriores debido fundamentalmente a la presencia, por ejemplo, de más lazos-nodos entre las categorías de Hijos Naturales e Hijos Legítimos y Valle Grande Zona Alta, Valle Grande Zona Baja.

Estas diferencias y similitudes expresadas a través de la densidad vincular de facciones (agrupamientos) entre particiones de la matriz pueden ser visualizadas en forma de grafo $^{16}$ utilizando el subprograma Netdraw, que se encuentra dentro del mismo paquete informático UCINET.

A continuación se exponen los cuatros grafos elaborados a partir de las actas bautismales correspondientes a los cuatro períodos temporales previamente delimitados.

16 Según lo ha definido Alsina, un grafo es una "estructura matemática determinada por unos puntos (o vértices) y por unas aristas o líneas entre alguno de estos puntos" (Alsina, 2011, p. 138). 


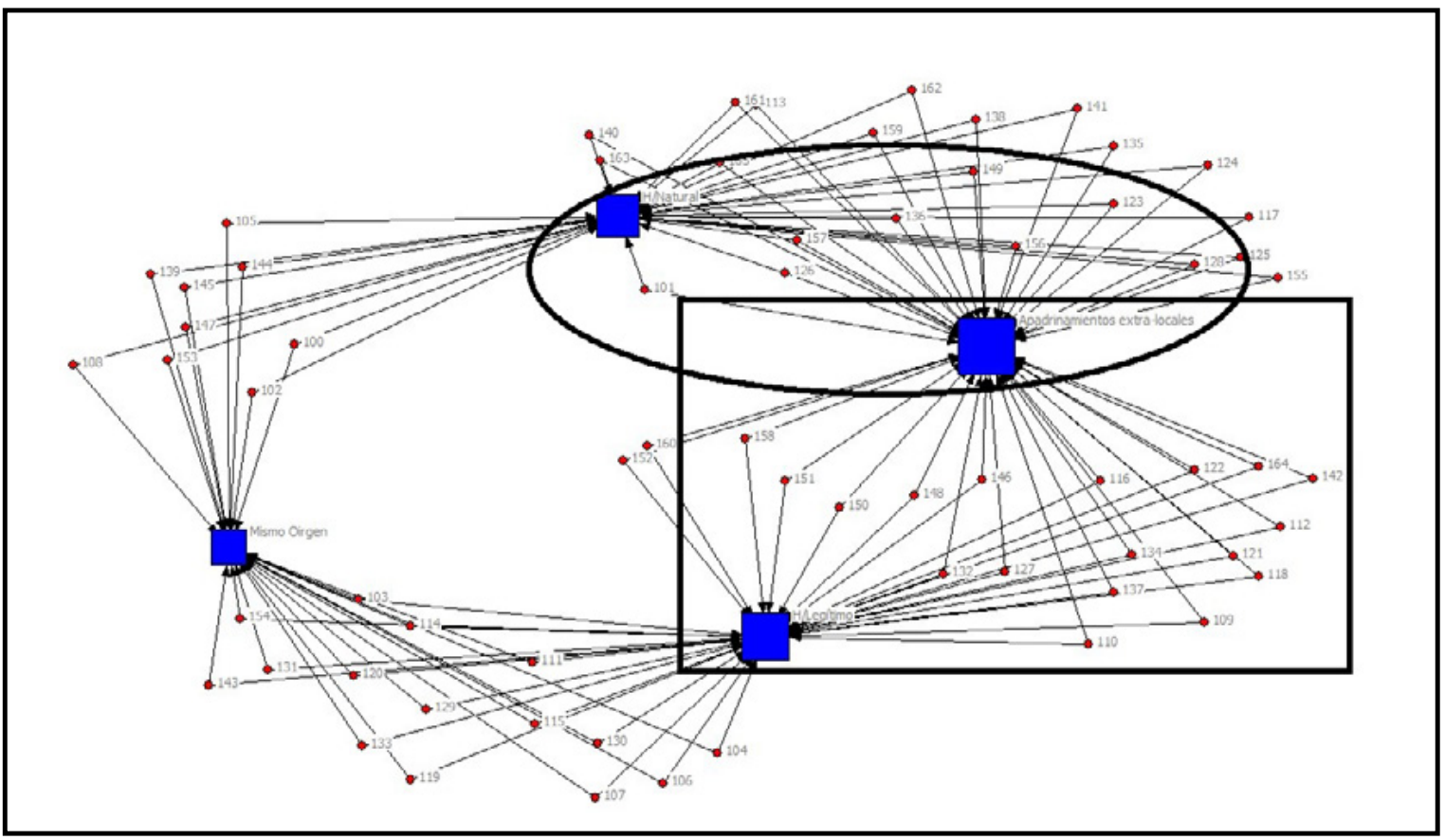

Figura 1. Red de apadrinamientos bautismales correspondiente al período I

(1902-1910). Fuente: Elaboración propia usando programa UCINET.

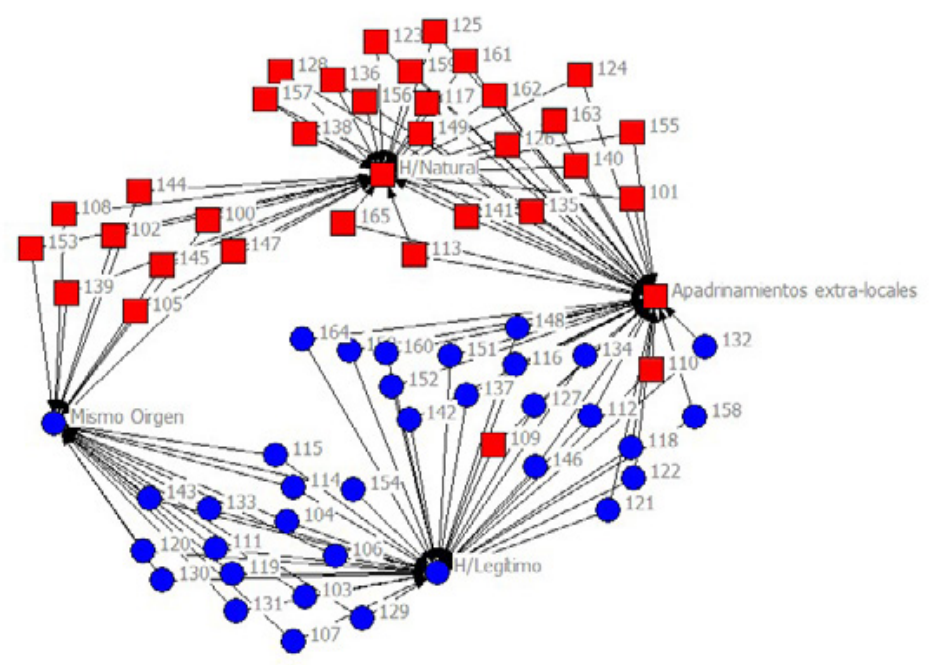

Figura 2. Red de apadrinamientos bautismales correspondiente al período I (1902-1910), diferenciada en dos facciones. 


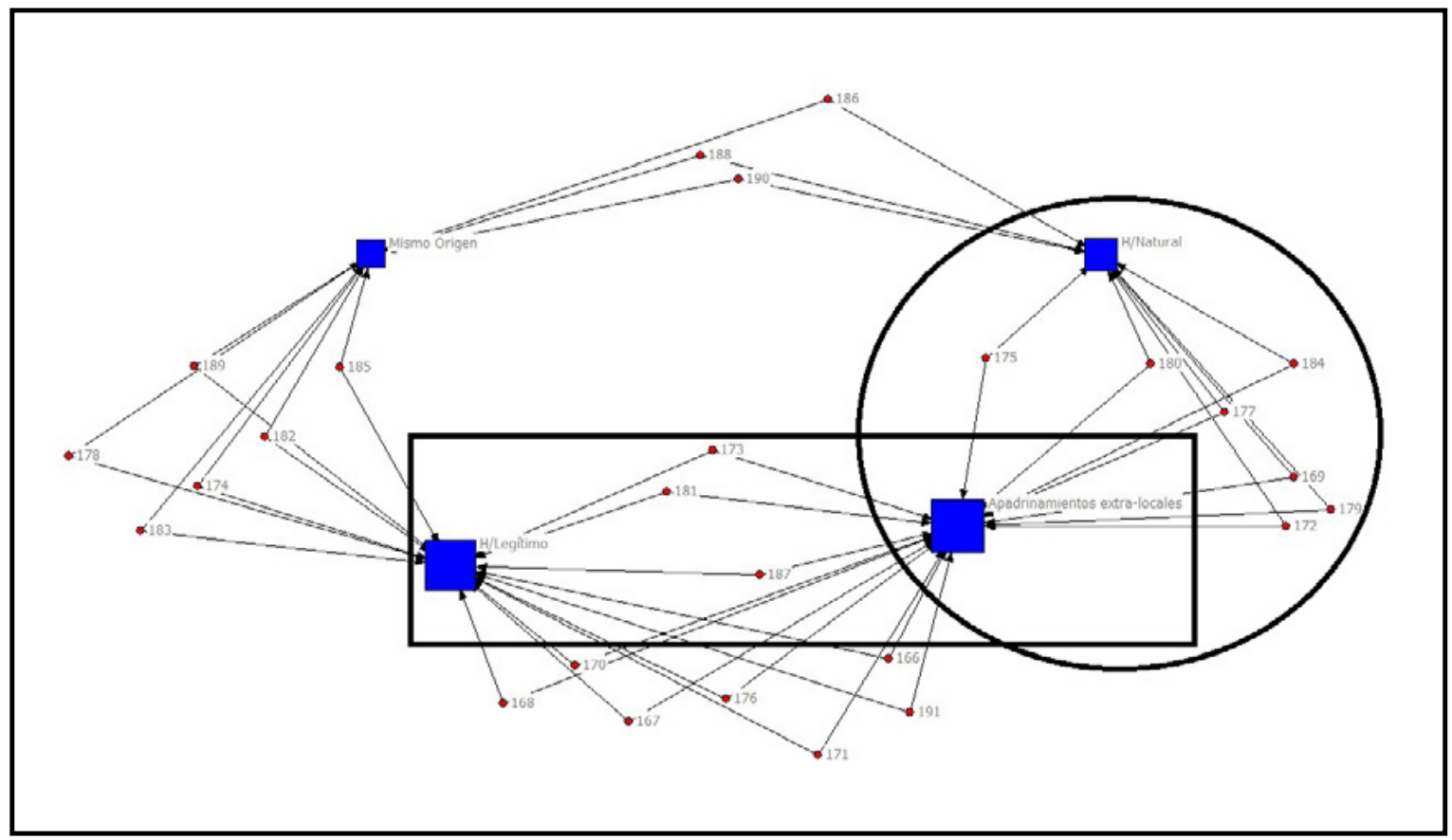

Figura 3. Red de apadrinamientos bautismales correspondiente al período II (1911-1922). Fuente: Elaboración propia usando programa UCINET.

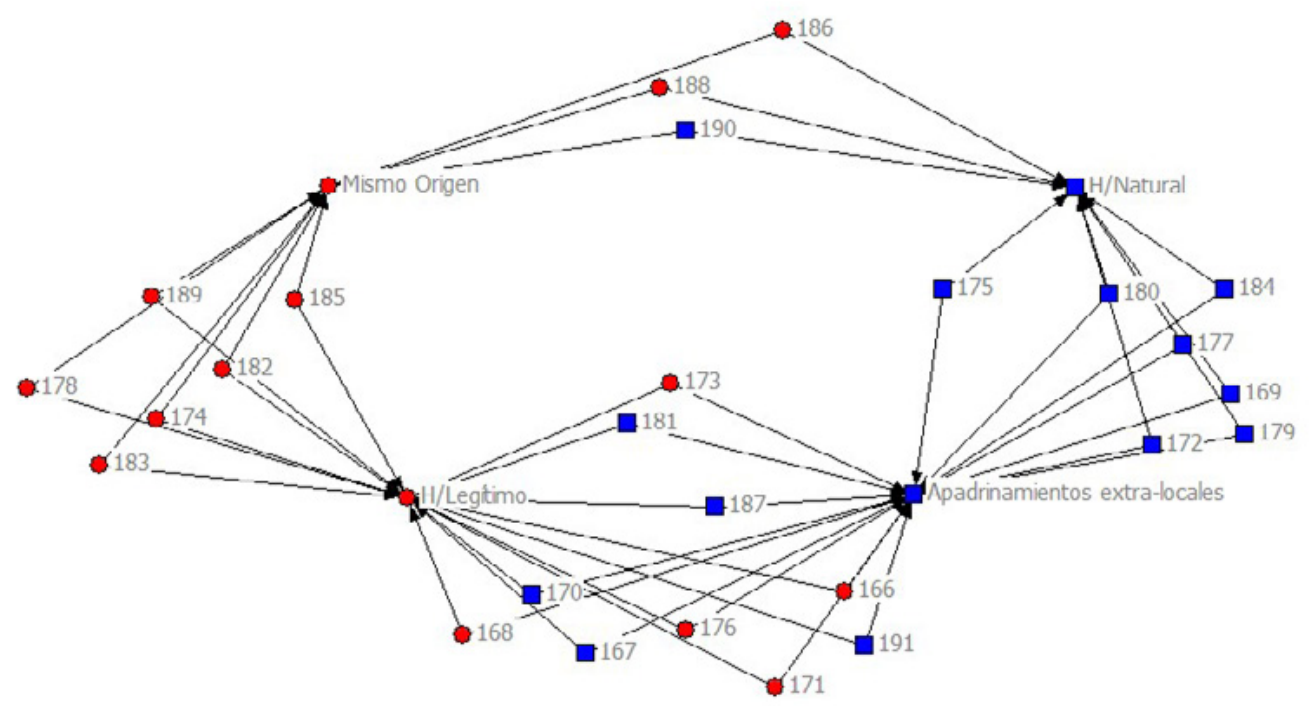

Figura 4. Red de apadrinamientos bautismales correspondiente al período II (1902-1910), diferenciada en dos facciones. 


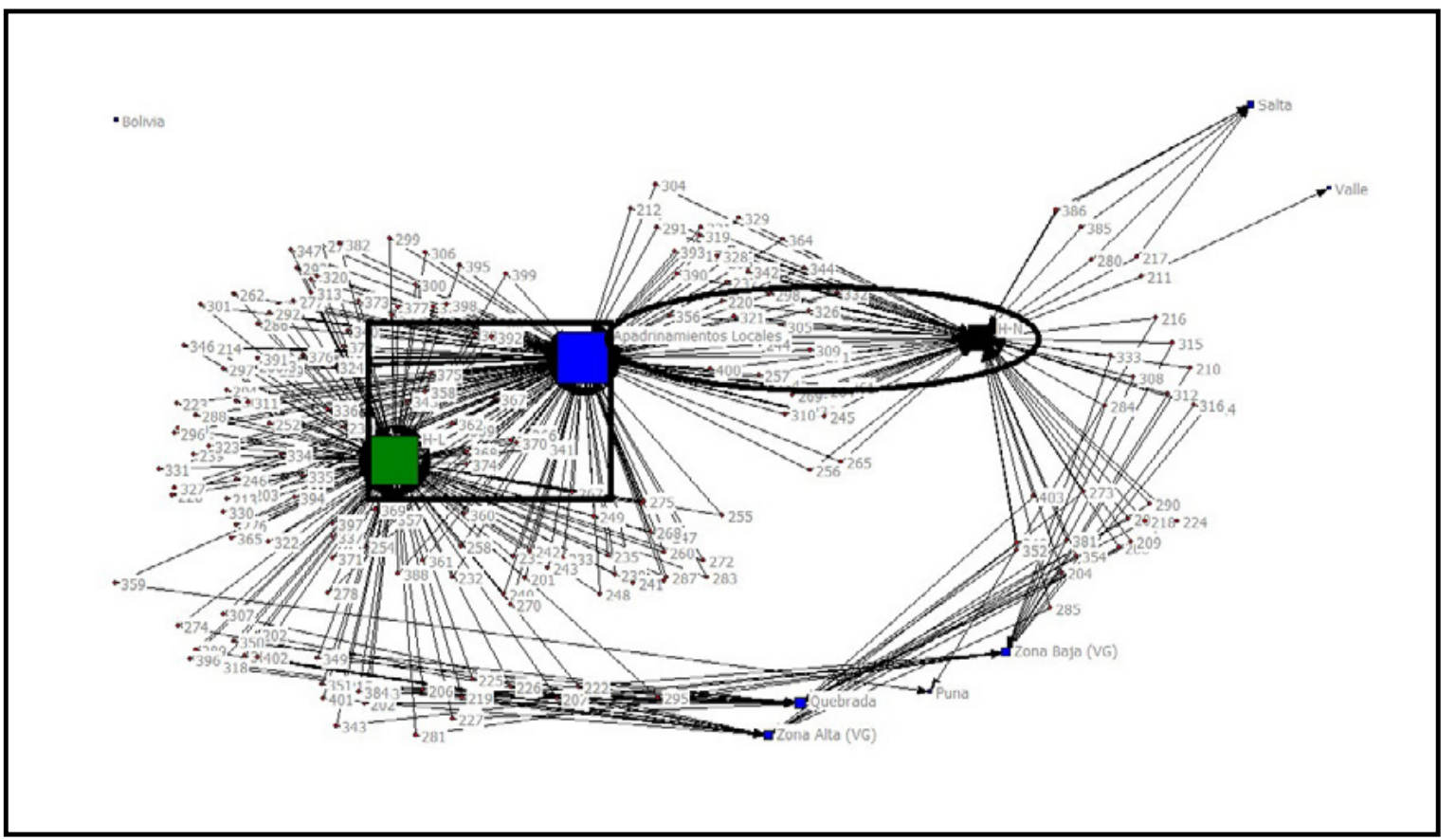

Figura 5. Red de apadrinamientos bautismales correspondiente al período III (1923-1930). Fuente: Elaboración propia usando programa UCINET.

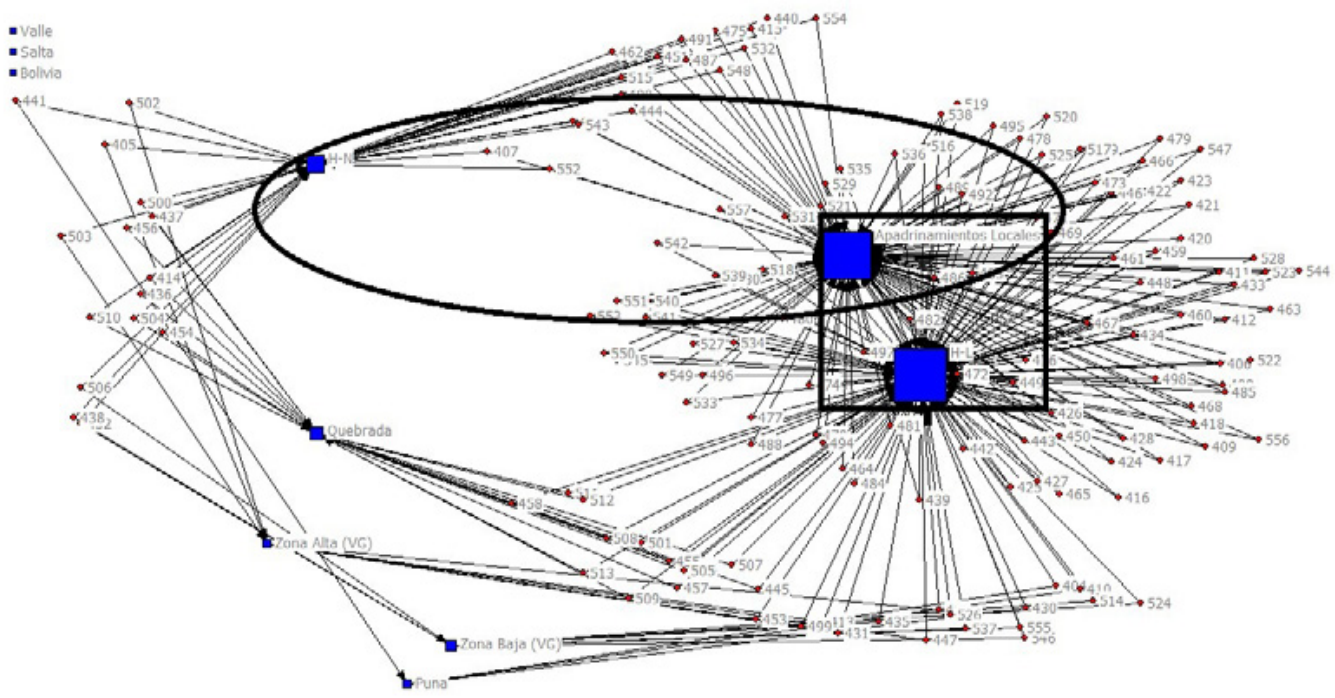

Figura 6. Red de apadrinamientos bautismales correspondiente al período IV (1930-1935). Fuente: Elaboración propia usando programa UCINET. 


\section{Análisis de la información visualizada en las figuras correspondientes a los períodos I, II, III y IV}

Las Figuras 1, 2, 3 y 4 correspondientes a los períodos I y II se correlacionan con la información presente en las tablas de centralidad de grado. Así pues, el nodo de mayor tamaño en ambos grafos es el que expresa la categoría Apadrinamientos Extralocales, seguidos por Hijos Legítimos (HN) e Hijos Naturales (HN). Ahora bien, nótese que en todas las redes se ha remarcado dos espacios. En el caso de las Figuras 1 y 3, la forma circular señala la distancia entre Hijos Naturales y Apadrinamientos Extralocales, mientras que la forma rectangular se encuentra demarcando la relación espacial expresada en distancias entre Hijos Legítimos y Apadrinamientos Extralocales. En estas dos primeras redes existe una mayor cercanía, es decir, una proximidad asociativa y una actividad receptiva similar entre las categorías referidas a los Apadrinamientos Extralocales y los Hijos Naturales de mujeres vallegrandinas. En el caso puntual de la red correspondiente al período II, esta asociación se encuentra mucho menos clara, ya que la cantidad de los datos es baja (solo 26 registros) y las diferencia numérica entre Hijos Naturales e Hijos Legítimos es mínima (11 HN y 15 HL). El estrecho margen de diferencia en tan pocos datos hace que la recepción de tan solo dos o tres nodos cambie sensiblemente las formas gráficas de los nodos rectangulares.

Las Figuras 2 y 4 expresan visualmente la partición de las matrices de datos de los períodos I y II en dos facciones para cada matriz. Los nodos de forma rectangular expresan una densidad mayor dentro de la red, y refieren a patrones similares de conexión que, en ambas redes, se vinculan a las categorías Hijos Naturales y Apadrinamientos Extralocales. La otra facción presente también en ambas redes muestra una densidad menor a los agrupamientos de nodos rectangulares, y ha sido referenciada con nodos de forma circular.

Los últimos dos grafos (Figuras 5 y 6) representan, como ya se ha señalado en las tablas de centralidad de grado, una imagen especular de las primeras redes. Aquí los círculos que remarcan los niveles asociativos y las cercanías entre nodos rectangulares se han transformado en una forma ovalada, dado que la distancia entre Apadrinamientos Locales e Hijos Naturales (HN) es cada vez más acentuada. Por el contrario, tal como lo expresan los recuadros, existe una evidente cercanía en el espacio topológico de la red entre las categorías Apadrinamientos Locales e Hijos Legítimos (HL).

Estas dos últimas redes presentan además una forma de distribución que las diferencia de los grafos correspondientes a los períodos I y II. En primer lugar se observa una mayor dispersión -aunque de menor densidad- de los vínculos entre HN, HL y otras categorías que en estos dos últimos grafos presentan un nivel de actividad relativamente bajo, como lo es el caso de Quebrada, Puna, Valle y las dos zonas de Valle Grande. Asimismo, debe tomarse en cuenta que determinadas categorías como Quebrada, Puna, Valle, Bolivia y Salta han sido subsumidas en los gráficos correspondientes a los períodos I y II bajo la categoría Apadrinamientos Extralocales, con lo cual la dispersión de los datos, al haber menos nodos rectangulares, se ha modificado.

Para finalizar este apartado, retomaré aquí la idea conceptual que permitió vincular la aplicación de la idea teórica acerca del capital social familiar, y este análisis formal de redes sociales; me refiero específicamente al constructo conceptual propuesto por Marc Granovetter sobre lazo débil y lazo fuerte. De acuerdo con la información analizada en las figuras de redes presentadas, la noción de lazo débil sería equiparable en este estudio con la relativa baja densidad vincular y actividad receptiva de los nodos rectangulares etiquetados como Apadrinamientos Extralocales e Hijos Legítimos. En oposición a esta relación débil, las categorías Apadrinamientos Locales e Hijos Legítimos (especialmente en las dos últimas figuras) pueden ser categorizadas como lazos fuertes en tanto las actividades receptivas y la densidad resultante de los patrones de conexión de ambas categorías sean similares. 


\section{Conclusiones}

Básicamente se pueden establecer dos bloques de información diferencial a lo largo del presente texto. En la primera parte se expusieron una serie de datos referidos a la dinámica demográfica particular de la unidad de análisis, seguido de una breve exposición histórica centrada en los principales hilos socioparentales locales como la marcada endogamia de pueblo y la familia extensa con residencia múltiple, ejes organizativos que parecen haber marcado las características estructurales del área Valle Grande a lo largo del tiempo histórico. A continuación se desarrolló un bosquejo teórico de la noción de capital social elaborada por Bourdieu, seguido de la noción elesiana de economía afectiva -lo cual implica reconocer el complejo relacional y multidimensional de los vínculos económicos y sus expresiones ligadas a los afectos dentro de los entramados sociales-. Ambas categorías teóricas permitieron deslizar el análisis teórico-conceptual hacia la noción de capital social familiar sobre la cual problematiza el citado trabajo de Furstenberg.

El nexo entre este primer bloque y el análisis de fuentes, seguido de la construcción de matrices y grafos, se encuentra bajo el subtítulo Capital social familiar y apadrinamientos bautismales. Es precisamente en este apartado donde se ha planteado la hipótesis general que guió el análisis posterior de los datos. Esto es, teniendo en cuenta los antecedentes teóricos y de investigación ya desarrollados, se planteó la idea de caracterizar las relaciones de apadrinamientos bautismales vallegrandinos a la manera de una red relacional de carácter afectivo y duradera en el tiempo (capital social familiar), basada en la movilización y mantenimiento de recursos y/o servicios (capital simbólico y económico), que tuvieron que exigir una inversión temporal y económica por parte de quienes conformaban y sustentaban esta red.

Fundamentalmente es posible establecer tres puntos nodales donde los conceptos teóricos señalados y el análisis de redes aplicado al tratamiento de los datos permiten dar una mayor profundidad y complejidad a las ideas rectoras que dieron origen a la presente pesquisa. Éstos son los siguientes:
1. En lo que respecta específicamente a las formas de las redes y sus expresiones métricas y gráficas, la tendencia existente entre cierta similitud de actividades receptivas, más el registro de facciones con mayor densidad entre los nodos rectangulares más prominentes dentro del período 1902-1910 y 1911-1922, parecen estar asociadas a relaciones fuertes (lazos fuertes) entre Apadrinamientos Extralocales e Hijos Naturales. Tal asociación, en términos analíticos, estaría marcando la presencia de pequeñas y progresivas grietas en el entramado fuertemente endogámico de los vínculos maritales y de compadrazgo que se dieron entre personas que residieron durante largos períodos temporales en el mismo poblado. Así pues, la caracterización basada en los rasgos relacionales que muestra la información bautismal puesta en red permite pensar en la aplicabilidad de una de las diferenciaciones elaboradas por F. Furstenberg en torno al capital social familiar, esto es: la necesidad teórica y metodológica de diferenciar entre los usos intrafamiliar (lo que sería el equivalente a lazos fuertes expresados bajo la forma de cierre de la red), de los vínculos sociales y el acceso a capitales sociales extrafamiliares a través de puentes (bridgin) que, durante los períodos descriptos, parecen estar representados en la figura de los padrinos y madrinas foráneos al área Valle Grande.

\section{Las dos últimas figuras representan, con una} escala mayor de datos, la tendencia contraria a lo señalado en el párrafo anterior. Esto es, una mayor lejanía y menor densidad (lazo débil) entre Apadrinamientos Extralocales e Hijos Naturales, y más cercanía (lazos fuertes) entre Apadrinamientos Locales e Hijos Legítimos. Sin embargo, en estas dos últimas redes se visualiza una persistencia y mayor diversidad de compadres y comadres foráneos al departamento Valle Grande.

3.El mapeo general de los vínculos, más la información provista por investigaciones sociohistóricas realizadas sobre el área de estudio, 
permiten pensar en algunos de los contenidos subyacentes a estas redes relacionales en lo referente a regularidades en la selección de padrinos/madrinas de bautismo por parte de mujeres y/o parejas progenitoras residentes en Valle Grande entre 1902 y 1935. Estas pautas o regularidades pueden ser enmarcadas dentro de las siguientes interpretaciones. Al ser la familia extensa con residencia múltiple y marcada endogamia de pueblo los ejes centrales de la organización parental de la unidad de análisis planteada, las relaciones fuertes entre Apadrinamientos Extralocales e Hijos Naturales pueden ser dilucidadas como un dispositivo vincular llevado a cabo en muchos casos (no en todos) por mujeres sin pareja progenitora consignada en las actas. Este dispositivo vincular ligado a la noción de capital social familiar se explica a partir del "vacío" relacional que pudo haber marcado la no presencia, al menos en términos de reconocimiento ante la institución eclesiástica, de la línea familiar del progenitor varón. Tal situación tuvo que haber impactado en los procesos de interreconocimiento entre personas residentes en el mismo poblado, con lo cual la necesidad de extender los lazos familiares a través de comadres y/o compadres foráneos al departamento pudo haber sido una opción para continuar la lógica vincular y de movilidad socioespacial sobre la que se sustentaron los lazos afectivos, económicos y simbólicos de estas familias extensas con residencias múltiples a lo largo de profundos períodos temporales.

Por último, es dable subrayar que el aporte fundamental del ARS y su aplicación en el campo de la reconstrucción de estas redes de capital social familiar está dado por la posibilidad real que nos brinda esta herramienta metodológica para reconfigurar de manera modélica las relaciones sociales a partir de información no seriada, fragmentada y descontinuada en el tiempo como lo son las fuentes trabajadas en esta investigación.

\section{Referencias citadas}

Albó, X., y Mamaní, M. (1980). Esposos, suegros y padrinos entre los Aymaras. En Bolton, R., y Mayer, E. (Eds.). Parentesco y Matrimonio en los Andes (pp. 283-326). Lima: Pontificia Universidad Católica del Perú.

Alsina, C. (2011). Mapas del metro y redes neuronales. Navarra, España: Editorial RBA, Coleccionable S.A.

Borgatti, P. y Everett, M. G. (1997). "Network analysis of 2-mode data". En Social Network, 19, 243-269. Consultado en: www.analytictech.com/borgatti/papers/ borgatti\%20-\%20network\%20analysis \%20 of\%20 2-mode\%20data.pdf

Borgatti, P., Everett, M. G., y Freeman, L. C. (2002-2007). Ucinet for Windows: Software for Social Network Analysis. MA: Harvard. Analytic Technologies.

Bourdieu, P. (2011). El capital social. Notas provisorias. En Las estrategias de la reproducción social. Buenos Aires: Siglo XXI.

Bourdieu, P. (2007). El sentido práctico. Buenos Aires: Siglo XXI.

Censo Nacional de la República Argentina (1914). Dirección Provincial de Estadísticas y Censos (DIPEC). San Salvador de Jujuy, Provincia de Jujuy.

Censo Nacional de Población, Hogares y Viviendas (2010). Dirección Provincial de Estadísticas y Censos (DIPEC). San Salvador de Jujuy, Provincia de Jujuy.

Cladera J. (2015). Trashumancia ganadera y negociación de identidades ante el estado en las sierras del Zenta (provincias de Jujuy y Salta). Tesis de Maestría aprobada por la Facultad de Filosofía y Letras de la Universidad Nacional de Buenos Aires, Argentina. Texto inédito.

Elias, N. [1987] 2009. El proceso de la civilización. Investigaciones sociogenéticas y psicogenéticas. México: Siglo XXI.

Fernández, F. (2010). Cuerpos endurecidos: fútbol, violencia ritual y tensiones identitarias en los valles orientales de Jujuy. Revista Cuadernos, 38, 111-126 Universidad Nacional de Jujuy, San Salvador de Jujuy. 
Fernández, F. (2013). Cambios y continuidades en las redes de padrinazgo en el oriente jujeño (Provincia de Jujuy-Argentina). En Actas del I Congreso Internacional: Nuevos Horizontes de Iberoamérica. Mendoza, Argentina.

Ferreiro, J., y Fernández F. (2013). Nupcialidad, compadrazgo y endogamia en las yungas de Jujuy (Noroeste de Argentina). Revista Caravelle. Cahiers du monde hispanique et luso-brésilien, 21-56. Toulouse, Francia: Ediciones Presses Universitaires du Mirail.

Freeman, C. L. (2002). "Detectando grupos sociales en datos cualitativos". En Gil Mendieta, J., y Schmidt, S. (Eds.). Análisis de redes. Aplicaciones en Ciencias Sociales. (pp. 23-40). México: UNAM.

Furstenberg, F. (2005). Banking on Families: How Families Generate and Distribute Social Capital. En Journal of Marriage and Family, 67(4). Department of Sociology. University of Pennsylvania. Published by National Council on Family Relations. Consultado en: http:// www.jstor.org/stable/3600240.

Golte, J. (2001). Cultura, racionalidad y migración andina. Lima: Editorial del Instituto de Estudios Peruanos (IEP).

Granovetter, M. (2000). "La fuerza de los vínculos débiles". Revista Politica y Sociedad, 33, 41-56.

Hanneman, R. (2001). "Centralidad y Poder". En Introducción a los métodos del análisis de redes sociales. Departamento de Sociología de la Universidad de California. Consultado en: http://wizard.ucr.edu/ rhannema/networks/text/textindex.html

Hanneman, R. (2001). Grupos y Sub-estructuras. En Introducción a los métodos del análisis de redes sociales. Departamento de Sociología de la Universidad de California. Consultado en: http://wizard.ucr.edu/-rhannema/networks/text/textindex.html

Lomnitz, A. L. (1994). Redes sociales, cultura y poder: Ensayos sobre Antropología Latinoamericana. México: Grupo Editorial Miguel Ángel Porrúa / Facultad Latinoamericana de Ciencias Sociales.

Molina, J., Muñoz, J., y Lozego, P. (2000). Red y Realidad. Aproximaciones al análisis de las redes científicas. En Actas del VII Congreso Nacional de Psicología Social. Oviedo, España.
Nutini, H., y Betty, B. (1989). Parentesco Ritual. Estructura y evolución histórica del sistema de compadrazgo en la Tlaxcala rural. México: Fondo de Cultura Económica.

Spedding, A. (1998). Contra-afinidad: Algunos comentarios sobre el compadrazgo andino. En Arnold, D. (Comp.). Gente de Carne y hueso, las tramas de parentesco en los Andes (pp. 115-137). La Paz, Bolivia: Edit. CIASE/ ILCA.

Teruel, A., Lagos, M., Peirotti, L. (2006). Los valles orientales subtropicales: frontera, modernización azucarera y crisis. En Jujuy en la Historia. De la colonia al siglo XX (pp. 435-464). San Salvador de Jujuy: Editorial de la Universidad Nacional de Jujuy.

White, D., Schnegg, M., Brudner, L., y Nutini, H. (2002). Conectividad múltiple, fronteras e integración: Parentesco y Compadrazgo en Tlaxcala Rural. En Gil Mendieta, J., y Schmidt, S. (Eds.). Análisis de Redes. Aplicaciones en Ciencias Sociales (pp. 41-94). México: Instituto de Investigaciones en Matemáticas Aplicadas y en Sistemas de la UNAM

Woolcock M., y Narayan, D. (2000). Social Capital: Implications for Development Theory, Research, and Policy. World Bank Research Observer, 15(2), 25-249. Consultado en: http://documents.worldbank.org/curated/en/961231468336675195/Social-capital-implications-for-development-theory-research-and-policy

\section{Fuentes consultadas}

Actas de bautismo correspondientes al Departamento Valle Grande. Período 1902-1935. Prelatura de Humahuaca, Provincia de Jujuy. 